\title{
Toward a Theory of the Pragmatic A Priori: From Carnap to Lewis and Beyond
}

\author{
Thomas Mormann
}

1. The Kantian Legacy. The notion of the a priori is an important legacy of Kant for modern philosophy of science. In the course of the $20^{\text {th }}$ century, a variety of proposals was put forward all of which claimed to overcome the inadequacies of Kant's original proposal of $a$ synthetic a priori for modern science. As Alberto Coffa put it in The Semantic Tradition from Kant to Carnap (Coffa 1991):

Wittgenstein's domain of showing, his later grammar, Carnap's syntax,
Sellars's categorial frameworks, and Kuhn's paradigms are some well-known
members of the continuing series of attempts to find the right way of
looking at that peculiar kind of knowledge that seems necessary and not
vacuous, yet at the same time does not quite state any factual claims. (Coffa 1991, 138).

Although this "peculiar kind of knowledge" is not scientific knowledge proper, it is related to scientific knowledge. To elucidate this relation is task of philosophy of science. Kant's account of the a priori reflected the sciences of his times, i.e. Newtonian mechanics and Euclidean geometry. Similarly, Poincaré, Reichenbach, Carnap, and others adapted their versions of the a priori element in empirical knowledge to the requirements of the sciences of their times. This is a general trait. If there is something like an a priori element, it would be rather implausible if it could be neatly isolated from the rest of empirical knowledge such that philosophers could investigate it independently of what is going on in the sciences themselves. The philosophical search for a priori elements in empirical knowledge can be sucessful only if philosophy has an eye on the specifics of the scientific knowledge of its time. The search for the a priori element will not be a matter of philosophical armchair investigations. Rather, explicating the a priori element is a matter of reconstructing the existing scientific knowledge, a kind of conceptual analysis of scientific knowledge. This 
entails that the a priori will be a moving or a relative a priori, depending on the actual state of scientific knowledge.

As point of departure I'll take a version of the a priori that has been rather neglected by contemporary epistemologists and philosophers of science, to wit, Clarence Irving Lewis's theory of the pragmatic a priori that he put forward in Mind and the World Order (1929) (henceforth MWO) and other works. Even if in contemporary philosophy of science we experience a sort of revival of the a priori, Lewis's account certainly does not occupy centre stage. I think that this state of affairs is less than optimal. Lewis was a figure that in some sense stood between the various philosophical currents that dominated philosophy of science in the early $20^{\text {th }}$ century, to wit, Logical Empiricism, American Pragmatism, and (Neo)kantianism. Hence, his position may offer a perspective from which new light may be shed on the intricate and multifacetted issue of the a priori.

In Dynamics of Reason (Friedman 2001) Michael Friedman put forward a proposal for an updated Kantian a priori. In very rough terms, Friedman's account of the a priori may be described as the result of a division of labour: Carnap's linguistic frameworks take care of the constitutive part, while a kind of regulative a apriori is taken from Cassirer's neokantianism plus some ingredients from Kuhn's historicism. One aim of my paper is to argue there are other successor concepts of the Kantian a priori in $20^{\text {th }}$ century philosophy of science that deserve to be reconsidered as well - in particular, if one is interested in connecting the $a$ priori with contemporary naturalistic accounts of scientific knowledge. Among them there is Lewis's pragmatic a priori, or so l'll argue. A reconsideration of Lewis's a priori seems promising for several reasons:

- Lewis's version of the a priori element of empirical knowledge is not too far away from that of Carnap and other logical empiricists. Hence it seems possible to employ our understanding obtained of the logical empiricist concept of the a priori also for the elucidation of its Lewisian cousin.

- Lewis's pragmatic a priori does not suffer from some of the deficiencies of the theoretically biased accounts of the a priori that emerged in the context of logical empiricism and Neokantianism. It takes care of the pragmatic aspects in scientific knowledge neglected by logical empiricism. 
- Lewis's pragmatic a priori may be used as a steppingstone to reach some contemporary accounts of the a priori that conceive it as a constitutive moment of the knowledge of an embedded reason - in contrast to the traditional "abstract" notions that explicitly or implicitly conceived reason as disembodied, abstract and theoretical.

In order to substantiate the last point I heavily rely on Hasok Chang's thought-provoking paper Contingent Transcendental Arguments for Metaphysical Principles (Chang 2008). Chang's reconsideration of Lewis's pragmatic a priori points to a dynamics of an embodied scientific reason. His account may be further elaborated by relating it to some concepts of contemporary cognitive semantics (cf. Lakoff 1986, Lakoff and Núñez 2000). Thereby an interesting relation can be established between the Lewis-Chang account of the pragmatic $a$ priori and certain ideas that first emerged in the category-theoretical foundation of mathematics (cf. Awodey 2010, Mac Lane 1986).

In a nutshell, then, my sketch of a modernized a priori starts from the traditional account that conceives the a priori as an element of a universal disengaged reason and eventually leads to a pragmatic a priori of a local embodied reason. More precisely, the outline of this paper is as follows: In the first section we will briefly recall the basic lines of the Neokantian and the logical empiricist discussions about the feasibility of a revised version of the Kantian a priori in the scientific context of the $20^{\text {th }}$ century. This sets the stage for dealing with Lewis's account of the a priori as presented in MWO and some earlier work. Then we will discuss the reconsideration of Lewis's ideas recently proposed by Chang in his Contingent Transcendental Arguments for Metaphysical Principles (Chang 2008). There, Chang proposes as a general format for a Lewisian pragmatic a priori so-called principle-activity pairs (henceforth P/A-pairs). These pairs make explicit the a priori principles that are necessary to carry out all kinds of epistemic activities relevant for science. The aim of the next section is to show that Chang's P/A-pairs can be fruitfully related with some recent developments in cognitive science, particular with Lakoff's and Núñez's theory of conceptual metaphors that guide the embodied rationality of creatures like us (cf. Lakoff 1986, Lakoff and Núñez 2000). Finally it is pointed out that conceptual metaphors, and thereby P/A-pairs and eventually Lewis's pragmatic a priori as well, have a natural formal explication in terms of functors in the sense of category theory (cf. Awodey 2010, Mac Lane 1986).

2. The A priori in Logical Empiricism and Neokantianism. According to their self-conception the various currents of Neokantianism were the philosophical heirs of Kant's philosophy 
whose "true essence" they claimed to preserve faithfully, while critically dismissing the obsolete features of the thought of their master. This self-image notwithstanding, fierce disputes arose among them what was to be understood as the true essence of Kantian philosophy. The Logical Empiricists, on the other hand, may be characterized as being in charge of arguing against all attempts to save the Kantian legacy from being sent to the philosophical dust bin.

In fact, this is a somewhat naïve picture of what really happened. On the one hand, one can hardly say that the various currents of Neokantianism undertook very serious efforts to faithfully preserve Kant's legacy. A particularly telling example is how they dealt with one of the cornerstones of the Kantian philosophical archictecture, to wit, the role of intuition for scientific knowledge. In direct opposition to Kant's original position, virtually all Neokantian currents intuition denied that intuition played any role whatsoever for scientific knowledge. This deviation from Kantian orthodoxy has far-reaching ramifications also, in particular for the issue of the a priori. On the other hand, at least some logical empiricist at least for some time in their career subscribed to rather Kantian positions, even if they did not call them as such. For instance, Carnap hold that a variant of Kantian intuition played an essential role in geometry and physics long after Neokantian philosophers had dismissed intuition completely. Another example of this stance is Reichenbach. Early in his career, he was engaged in a partial defense of the Kantian a priori when he proposed to distinguish in Kant's a priori an apodictic and a constitutive moment. For him, the fact that the a priori was a "contribution of reason was "not expressed by the fact that the system of coordination contains unchanging elements, but in the fact that arbitrary elements occur in the system" (Reichenbach 1920/1965, 88-89). Virtually all philosophers who sought to maintain an a priori moment in scientific knowledge accepted a similar modification, for instance, C.I. Lewis: independently of Reichenbach but almost at the same time, he argued for a non-apodictic pragmatic a priori (cf. Lewis 1923, 1929).

Perhaps the most famous dispute between Neokantians and Logical Empiricists on issues concerning the Kantian a priori was the one between Schlick's and Cassirer's dispute on the "empiricist or criticist interpretation of relativity theory" (Schlick 1921, Cassirer 1921). Schlick argued that Einstein's relativity theory had shown once and for all that any kind of a Kantian a priori was untenable. If a Neokantian wished to save a Kantian conception of philosophy of science he should propose a new constitutive and apodictic a priori. Otherwise he should renounce any version of an a priori element in scientific knowledge. In other words, 
for Schlick, in his anti-neokantian bias, apodicticity was an essential feature of the a priori. Thereby he missed the interesting point of the postkantian evolution of this concept in $20^{\text {th }}$ century philosophy of science, namely the various attempts to formulate a non-apodictic but nevertheless non-trivial a priori.

Philosophers of quite different taste and orientation were engaged in this endeavor (cf. Coffa 1990). In this paper l'd like to deal only with Carnap, Cassirer, and Lewis. A more detailed comparison of their different positions cannot be given in advance. Instead, in this section I am content to give a rough classification by locating them in the following table that describes their respective atttitudes with respect to certain important features of the a priori:

\begin{tabular}{lcccc} 
A PRIORI: & apodictic & constitutive & regulative & pragmatic \\
\cline { 2 - 4 } Kant & yes & yes & yes & no \\
Cassirer & no & $?^{1}$ & yes & (yes) \\
Carnap & no & yes & no & no \\
Lewis & no & yes & no & yes
\end{tabular}

Some remarks on this schema may be in order. In th $20^{\text {th }}$ century virtually philosophers of science have given up the requirement of apodicticity. This is the only common feature shared by all authors. Further, I contend that Cassirer, Carnap, and Lewis maintained that the a priori entails some kind of constitution. With respect to the regulative moment of the $a$ priori their ways diverge. In Carnap and Lewis no regulative a priori can be found. For Cassirer, the situation was more complex. While Kant neatly distinguished between the constitutive and regulative principles by conceiving the former one as belonging to the faculty of understanding (Verstand) and the latter one to the faculty of reason (Vernunft) for Cassirer this Kantian distinction was not available. Rather, he gave a peculiar regulative twist to the constitution through relative converging invariants. According to him, the various stages of a relativized constitutive a priori internally converged to a limit somehow in the way as a Cauchy-convergent series of elements of a space approximates its limit (cf. Mormann 2010). Thereby "in the end" science will arrive at something quite close to the $a$ priori in the original Kantian sense (cf. Friedman 2001). In contrast to Kant, however, Cassirer did not consider an immutable system of a priori categories as a terminus a quo but

\footnotetext{
${ }^{1}$ There is no unanimity in this point. Friedman contends that Cassirer's a priori lacks any constitutive trait but only retains a regulative a priori (cf. Friedman 2001, 66). With Ihmig I prefer to interpret Cassirer's "relative invariants“ as a constitutive relativized a priori (cf. Ihmig 1997, 246f).
} 
as a terminus a quem to be reached at the end of the conceptual evolution. Up to now, the problem of whether there are pragmatic aspects in Cassirer's account of scientific knowledge has hardly been considered. I contend that at least some kind of "theoretical pragmatism" may be attributed to him: according to his critical idealism, there was no experience of the given without concepts, and these concepts were a priori devices for the constitution of (relative) unity. They did not describe reality that was independent of us, but were rules that guided our activity:

[Scientific] concepts are valid, not in that they copy a fixed, given being, but in sor far as they contain a plan for possible constructions of unity (my emphasis) which must be progressively verified in practice, in application to the empirical material. ... We need, not the objectivity of absolute things, but rather the objective determinateness of the method of experience. (Cassirer 1910, 322)

The pragmatic component in Cassirer's account of the a priori is encapsulated in the claim that "valid" concepts contain "plans for possible constructions of unity". Concepts are not descriptions but blue prints for further experiences. Plans are or depend on certain a priori. For him, concepts are plans for constructing an ever more thorough unity of scientific knowledge. To put it bluntly, concepts are devices for achieving certain goals, namely, to bring about an ever more comprehensive and profound unity of scientific knowledge. Hence it does not seem inappropriate to characterize Cassirer as a "theoretical pragmatist" for whom the aim of scientific activity was not to produce a faithful description of the world, but to bring about more and more comprehensive and unifying experiences. From a modern point of view, his emphasis on coherence and comprehensiveness as the most important values of the scientific enterprise may be criticized as somewhat one-sided, the important point of encounter is that for Cassirer's Neokantianism as well as for Lewis's pragmatism scientific knowledge, action and evaluation are essentially connected (cf. Lewis 1946, 5).

3. Lewis's Pragmatic A Priori. In his days Lewis (1883 - 1964) was one of most prominent American philosophers. Today he is much lesser known than the other three classical great pragmatists Peirce, James and Dewey. So some introductory remarks on his life and 
philosophy may be in order. ${ }^{2}$ Lewis may be characterized as the most Kantian of all pragmatists although of a rather peculiar kind. He is reported to have characterized himself as "a Kantian who disagrees with every sentence of the Critique of Pure Reason." Beside Peirce he may be said to have been the "most logical" pragmatist. After having finished his dissertation The Place of Intuition in Knowledge (1911) under Royce his research interests switched to logic. He spent a lot of work to overcome the shortcomings of the standard extensional logic. Indeed, Lewis was one of the founding fathers of modern modal logic. More generally, he considered the question of what should be considered as the "correct" logic of science or of our everyday reasoning as an empirical problem the solution of which had to take into account the empirical facts of the practice of scientific investigation.

In the early 1930s he contacted Schlick and Carnap and invited them to make an effort to overcome the gap between the two philosophical currents of Logical Empiricism and American Pragmatism. For him, practice played a constitutive role in experience. In agreement with all other classical pragmatists Lewis contended that experience is active and interferential. It is shaped by interactions with our surroundings and our specific interests and habits as agents. Beside the strict separation between facts and values, this thesis was one of the key differences between the two traditions of scientific philosophy of logical empiricism and pragmatism. In the end, this project was less than successful. Both movements did not succeed in finding a closer rapprochement and remained reserved allies each pursuing its own projects. For a final assessment of this issue from Lewis's side, see (Lewis 1941).

A first sketch of his theory of a pragmatic a priori is to be found in his paper A Pragmatic Conception of the A priori (1922). In mature form it is presented in Mind and the World Order (1929) Further elaborations may be found in his later book An Analysis of Knowledge and Valuation (1946). Let's start with a quote from (MWO) in which he subscribed to a nonapodictic interpretation of the a priori rather similar to the one that Reichenbach had put forward somewhat earlier:

„The a priori ... represents the contribution of the mind itself to knowledge, it does not require that this mind be universal, or absolute ... . The determination of the a priori is in some sense like free choice and deliberate action" (MWO, 231, 233).

\footnotetext{
${ }^{2}$ For comprehensive presentations of Lewis's life and work the reader may consult Murphey (2005) or Rosenthal (2007); for a succinct presentation of Lewis's philosophy, and a comparison of his views with those of Carnap and Quine, the reader may consult Baldwin (2007).
} 
Lewis's a priori kept only the constitutive element, apodicticity is given up, and intuition plays no role in it. For Lewis, the a priori was a variable that might change over time. Even the a priori principles of logic were not beyond the possibility of alteration. This was not merely an abstract possibility - Lewis was one of the leading figures in promoting alternative logics differing from that of the Principia.

Although no longer apodictic, Lewis's a priori kept a conditional kind of necessity. The a priori is true no matter what experience may bring. The acceptance of a concept as a priori is a matter of decision or legislation, something for which there are alternatives, but for which the criteria are not empirical but pragmatic. This necessity of the a priori has nothing to do with inescapability.

The paradigm of the a priori in general is the definition. It has always been clear that the simplest and most obvious case of truth which can be known in advance of experience is the explicative proposition and those consequences of definition which can be derived by purely logical analysis.

If experience were other than it is, the definition and its corresponding classification might be inconvenient, useless, or fantastic, but it could not be false. (MWO, 239)

For Lewis, mathematics provided the best examples for such an analytical a priori. One may say, Lewis asserted, that the traditional conceptions of the a priori are the "historical shadow of Euclidean geometry" (MWO, 240-241). But Euclidean geometry gave the wrong impression that the a priori was unique and apodictic. The invention of a plurality of non-Euclidean geometries evidenced that the true a priori of scientific knowledge was an a priori of a different kind, which lacked uniqueness and apodicticity (MWO, 242). Rather, an essential feature of the a priori component in knowledge was that it could have been chosen differently. Although mathematics provided a good example of the a priori element, Lewis emphasized that the a priori element in the empirical sciences went far beyond the mathematical:

All order of sufficient importance to be worthy of the name of law depends eventually upon some ordering by mind. Without initial principles by which we guide 
our attack upon the welter of experience, it would remain forever chaotic and refractory. In every science there are fundamental laws which are a priori because they formulate just such definitive concepts or categorial tests by which alone investigation becomes possible. (MWO, 254)

As an example of such an operational a priori Lewis discussed in detail Einstein's definition of simultaneity for events at a distance. ${ }^{3}$ For him, it was a stipulation that one could make of one's own free-will in order to arrive at a definition of simultaneity (cf. MWO, 256). Hence Einstein's operational definition of simultaneity was an a priori law. Only by presupposing such laws one could enter upon the investigation by which further (empirical) laws were sought. This led him to the following sweeping generalization:

Indeed all definitions and all concepts exercise this function of prescribing fundamental law to whatever they denote, because everything which has a name is to be identified with certainty only over some stretch of time. (MWO, 257)

The a priori element in knowledge is present whenever there is classification, interpretation, or the distinction of real from unreal - which means that it is present in all knowledge (cf. MWO, 266). Lewis vigorously that a priori laws could be abandoned if the structure, which was built upon them, did not succeed in simplifying our interpretation of the phenomena. Thereby he arrived at a kind of Kuhnian description of a revolutionary change in science forced by the pressure of new "anomalic" experience that does not fit well in the old framework:

Beyond the principles of logic and pure mathematics ... there must be further and more particular criteria of the real prior to any investigation of nature. Such definitions, fundamental principles and criteria the mind itself must supply before experiences can even begin to be intelligible. These represent more or less deeplying attitudes, which the human mind has taken in the light of its total experience up to date. But a newer and wider experience may bring about some alteration of these attitudes even though by themselves they dictate nothing as to the con-

\footnotetext{
${ }^{3}$ Recently, David Stump reconsidered and defended Lewis's interpretation of Einstein's definition of simultaneity (cf. Stump 2003).
} 
tent of experience, and no experience can conceivably prove them invalid. (MWO, 266)

Even if Lewis did not use this term, his account of a comprehensive a priori, which goes well beyond formal logic and mathematics, points towards a sort of transcendental logic similar to the one that Cassirer had put forward in his programmatic paper Kant und die moderne Mathematik (Cassirer 1907).

This brief review of the most important features of Lewis's pragmatic a priori suggests that it provided a framework for the conceptual and practical activities and operations of a community of scientists for some time. The pragmatic a priori determined what was to be understood as a meaningful problem and what counted as a solution, what methods were considered as admissible and what were the standards according to which the results were assessed. If the pressure of recalcitrant experiences became too strong, it could be given up and replaced by another one. In sum, the Lewisian a priori exhibited certain similarities with a Kuhnian paradigm. This result, after all, should not come out as overly surprising. On the contrary, it may be considered just as a confirmative extension of Coffa's catalogue of the various attempts of improving Kant's original notion of the a priori we quoted in section 1.

\section{Contingent Transcendental Arguments for Metaphysical Principles. ${ }^{4}$ In his paper Contingent} Arguments for Metaphysical Principles (Chang 2008) the author endeavors to update Kant's transcendental arguments for the a priori in such a way that it takes into account to particular and contingent epistemic circumstances of the cognizing subject. According to Chang, such contingent arguments for metaphysical principles may be cast in the following form (cf. Chang $(2008,113)$.

- If we want to engage in a certain epistemic activity, then we must presume the truth of some metaphysical principles.

As point of departure he takes Lewis's "conceptual pragmatism" based on the central notion of the "pragmatic a priori". Going beyond Lewis's discussion, Chang proposes as an essential task of a theory of the pragmatic a priori to give an account of the "epistemic and conceptualizing activities of an embodied subject", i.e. an epistemic subject that has to come to terms with the contingent conditions of a spatio-temporal material world in which it is living.

\footnotetext{
${ }^{4}$ The title of this section is borrowed from Chang (2008).
} 
For such a subject the a priori makes sense only in a contingent way, not as a universal condition of cognition in general, but as a local factor of particular brands of cognition (ibid. 122).

Chang criticizes the Kantian universal and apodictic a priori to have ignored this local character of our cognition and to have been overly impressed by the then dominating Newtonianism, thereby conceiving some temporarily useful scientific ideas of limited scope as deep "metaphysical truths" (ibid. 114). Thus, with respect to the a priori, and more generally with respect to admissible scientific procedures and intelligible concepts, science has to educate philosophy of science, and not vice versa. This insight is actually not new, it may already be found in the writings of otherwise so divergent philosophers of science such as Philipp Frank and Ernst Cassirer.

After these general remarks let us now consider a simple example of Chang's contingent transcendental "If-then"-arguments, a version of which can already be found in Lewis (cf. Lewis 1923, 233-234) and whose ramifications in terms of cognitive science will be discussed further in the following sections:

- If we want to count things, we have to assume that they are discrete.

Otherwise, the activity of counting is simply impossible and unintelligible. In other words, discreteness is a metaphysical principle that we have to presuppose if we want to engage in the activity of counting. This necessity is a conditional pragmatic necessity. If we were jelly-fish, we would probably not engage in the task of counting, as already Lewis suggested (cf. Lewis 1929, 252). As Chang points out, the principle of discreteness is not empirical; it says nothing about the world itself, only that we need to take it as discrete, if we are going to count things (cf. Chang 2008, 123). In first approximation, then, a theory of the pragmatic a priori has the task of providing us with a comprehensive, perhaps even complete list of "principleactivity" pairs (henceforth P/A-pairs). Some of the P/A-pairs considered by Chang are gathered in the following list (cf. Chang 2008, 125ff):

$\begin{array}{lll}\text { - } & \text { Metaphysical Principle } & \text { Epistemic Activity } \\ \text { - } & \text { Discreteness } & \text { Counting } \\ \text { - } & \text { Uniform Consequence } & \text { Prediction } \\ \text { - } & \text { Sufficient Reason } & \text { Explanation } \\ & \text { Subsistence } & \text { Narration }\end{array}$


- $\quad$ Transitivity

- Non-Contradiction
Ordering

Assertion

In "real science" we are hardly ever engaged in carrying out these activities in isolation. Rather, the activities of real mathematics, physics, or of any other science are more complex than those mentioned so far. Hence, the sketch of a theory of the pragmatic a priori presented so far may seem to be utterly simplistic. Here, Kuhnian paradigms may come to the rescue. More precisely, I propose to conceive Kuhnian paradigms as complex systems of pragmatic a priori elements or systems of $\mathrm{P} / \mathrm{A}$-pairs that determine the scientific practice of a scientific community for some time. A scientific revolution takes place when essential components of such a system are replaced by new ones under the pressure of anomalies:

In the typical case in which old methods of interpretation are discarded in favor of new ones, it requires new empirical data, which offer some difficulty of interpretation in the old terms, to bring about the change. ... The advantage of the change must be considerable and fairly clear in order to overcome human inertia and the prestige of old habits of thought. (MWO, 269)

An important trigger for changing an established system of pragmatic a priori elements is the invention of new machines, measuring instruments and experimental set ups. They often lead to totally new problems, perspectives, and solutions. As examples Lewis briefly mentioned the invention of the telescope and microsope that brought it about that our categories of perception changed for ever (cf. MWO, 268). Since the advent of "Big Science" the importance of this kind of "instrumental a apriori" has steadily grown. To have some concrete examples, one may think of a particle colliders designed to collide particle beams, or the new types of protein sequencers in molecular biology. These machines allow us to formulate questions and to solve problems that before these devices came into being did not make sense at all. These machines provide complex material a priori elements that determine for some time the practice of a scientific community. A still other type of machine-based pragmatic a priori are provided by the various novel methods of calculation and simulation that are indispensable tools for the constitution of many results in the advanced empirical sciences. 
5. The Structure of the $A$ priori according to Cognitive Semantics. According to Chang's account, the pragmatic a priori element of a scientific discipline is given by a system of P/Apairs. Generally, these pairs may be characterized as devices that are used to organize the cognitive activities that a subject carries out to achieve certain goals. In first approximation, then, a theory of the a priori elements of scientific knowledge should provide lists of those P/A-pairs that help to organize important cognitive enterprises such as mathematics, physics, and other sciences.

Fortunately, philosophy of science is not alone in the task of developing a comprehensive theory of the "epistemic activities of an embodied subject and their underlying principles" from scratch. For some two decades now, cognitive scientists have been engaged in the task of elaborating such a theory as part of what has been called cognitive semantics conceived as an empirical theory of the rationality of embodied subjects (cf. Lakoff 1986, Lakoff and Núñez 2000). For reasons of space the following brief remarks on the issue of embodied rationality must suffice. In contrast to the traditional approach in epistemology that conceives reason as abstract and disembodied the new account emphasizes that

- Thought is embodied, that is, the structures used to put together our conceptual systems grow out of bodily experience and sense in terms of it; moreover, the core of our conceptual systems is directly grounded in perception, body movement, and experience of a material and social character.

- Thought is imaginative, in that those concepts that are not directly grounded in experience, employ metaphor, metonymy, and mental imagery - all of which go beyond the literal mirroring, or representation, of external reality. ... Every time we categorize something in a way that does not mirror nature, we are using general human imaginative capacities. (Lakoff 1986, xiv)

The embodied human reason grows out of our biological nature. ${ }^{5}$ This fact not only marks the more mundane parts of human reason and rationality such as everyday common sense

\footnotetext{
${ }^{5}$ The embedded character of human reason is, of course, not fully described by biological constraints. At least as important are social and historical factors of various kinds. These factors determine, to a large extent, what is assessed as rational and what is not in a given historical situation. A further determinant of a more general character is the finitude of human beings: our capacities of reasoning are
} 
reasoning, but also the more theoretical and abstract ramifications of human reasoning, e.g. mathematics. Lakoff and Núñez's key notion is the notion of conceptual metaphor. Conceptual metaphors enable us to use the inferential structure of one conceptual domain (say, geometry) A to reason about another domain B (say, arithmetic). According to them conceptual metaphors are the basic devices for mankind to come to terms with the evergrowing conceptual complexities of its life-world.

An elementary example is the "number line". The "number line" is the conceptual metaphor that conceptualizes "number facts" and "number relations" in terms of "geometrical facts" and "geometrical relations". Geometry - understood in a modest sense as sort of common sense knowledge about spatial facts and processes - may be considered as a more familiar realm to us than numbers, which are usually conceived as entities that are more abstract and more remote from our ordinary experience. We are accostumed with the qualitative concepts of distance, movements, neighborhood and the like long before we can trust in our capicity of dealing with numbers. Hence it might help us a lot if we could employ our capacities of coming to terms with geometrical problems when we are dealing with "number problems", i.e. if we could transfer the inferential patterns that we have used successfully for solving geometrical problems to the realm of numbers in order to solve the more abstract arithmetical problems arising there.

Let us denote such a conceptual transfer by $A \Rightarrow B$, with $A$ denoting the source domain of geometry, B the target domain of numbers, and $\Rightarrow$ the conceptual transfer from A to B. I propose to interpret conceptual metaphors $A \Rightarrow B$ as principle-activity pairs $P / A$ : The inferential structure of the source domain A plays the role of (a system of) a priori principles that are used to organize the conceptual praxis of the target domain B. Or, in other words, a conceptual metaphor $A \Rightarrow B$ encapsulates the program of organizing the exploration of $B$ along guidelines that are proposed by the inferential patterns of the source domain $A$. In our case, this amounts to the attempt to deal with number problems by using conceptual devices borrowed from geometry. Whether this attempt will be successful cannot be known in advance. Rather, it is an empirical contingent fact (or not).

severely limited by restrictions of time, memory, lack of acuity, interest, energy and so on. All these factors contribute to the fact that human reason and rationality is rather different from an idealized universal general reason. If we want to investigate the a priori element and its role for human knowledge all of them had to be taken into account In this paper l'll only deal with the "biological embeddedness" of human reason seen from the perspective of cognitive science leaving for another occasion a broader account that also deals with the other ingredients. 
Let us now consider in some detail how this works in the case of the geometrization of numbers (cf. Lakoff and Núñez 2000, Chapter 3). In their book Where Mathematics Come From Lakoff and Núñez offer an elaborated account of how large parts of mathematics may be conceived as arising from a complex net of constituting conceptual metaphors. Even for the constitution of elementary arithmetic they invoke not less than four grounding metaphors. In this paper only a succinct sketch of how constitution through conceptual metaphors works. Hence I am going to deal only with the so called "Measuring Stick metaphor" that may be characterized as a geometric metaphor in the sense that its source domain refers to elementary spatial structures and the inferences valid for them.

The measuring stick metaphor is based on the age-old practice of using a measuring stick or string for determining the lengths of various objects for practical purposes such as housebuilding, measuring physical distances etc. Thereby a stick or a string is used as a unit from which other lengths are derived as multiples. The stick or the string as a physical segment is the basic ingredient for a system of inferences that is applied to the domain of numbers by a kind of metaphorical translation manual (cf. Lakoff and Núñez 2000, 69):

- $\quad$ Physical Geometry

- Physical segments

- The basic physical segment

- The length of a physical segment

- Longer, Shorter

- Acts of physical segment placement

- A physical segment
Arithmetic

Numbers

One

The size of a number

Greater, Less

Arithmetic operations

The result of an arithmetic operation

These metaphorical correspondences lead, among other things, to the assumption that the concatenation of numbers has to be associative and commutative, since the corresponding concatenation of physical segments is. "Numbers" that do not fulfil these requirements are not considers as "real" numbers. A less elementary consequence is that a priori operations with physical segments are interpretable as arithmetical operations, and vice versa, that meaningful arithmetical operations should allow an interpretation in terms of manipulation of physical segments leads to the conclusion that the diagonal of a square with sides having length 1 also has a length, i.e. does represent a well-defined number, to wit, $\sqrt{ } 2$. This holds, even if we are unable to calculate $\sqrt{ } 2$ precisely, since it is "irrational". 
One would considerably underestimate conceptual metaphors if one would take them just as devices for rendering plausible some more or less trivial pieces of elementary mathematics. In order to overcome this prejudice one may point out that Dedekind's completion of the rational numbers through his famous construction of all real numbers by "Dedekind cuts" may be conceived as based on some conceptual metaphors (cf. Lakoff and Núñez (2000, 292ff). Dedekind's method of completion is in no way restricted to the special case of the completion of rational numbers. As was pointed out already by Cassirer (Cassirer 1907) and amply confirmed by the evolution of $20^{\text {th }}$ century mathematics after Cassirer, the method of Dedekind completion may be considered as the prototype of a profusion of "idealizational" constitutions that turned out to be an essential ingredient of modern mathematics in general (cf. Mormann 2008). This evidences that the reconstruction of mathematical ideas in terms of conceptual metaphors can hardly be dismissed as a merely pedagogical device.

Conceptual metaphors do not live in isolation. They can be combined in various ways leading to ever more complex conceptual systems as is shown in detail by Lakoff and Núñez by detailed reconstructions of higher mathematical concepts as constituted by complex layers of conceptual metaphors.

There is no guarantee that metaphorical constitutions always work. A constitutive conceptual metaphor $(A \Rightarrow B)$ may fail in organizing the target domain $B$ in accordance with the rules suggested by $A$. Then it is expedient to replace either the source domain $A$ or the target domain $B$ in some way or other, replacing the original metaphor by one that is pragmatically better suited. Most often the failure is a matter of degrees, i.e. the validity of a metaphor turns out to be limited. For instance, the container metaphor for sets is useful to some extent but fails if it is pushed too far. The guiding conceptual metaphors that constitute the epistemological practice of a discipline need not meet the eyes of a casual observer. Rather, they have to be reconstructed by a metaphorical analysis, so to speak, which uses to be a non-trivial task.

This description of the aim and structure of conceptual metaphors $A \Rightarrow B$ should suffice to make plausible the thesis that conceptual metaphors closely resemble P/A-pairs. Both P/Apairs and conceptual metaphors $A \Rightarrow B$ exhibit a similar binary structure, and both serve as organizing the practice of their target domains according certain guidelines that are considered as a priori. For P/A-pairs the a priori element is characterized as a metaphysical principle that enables us to carry out a certain activity, and in the case of conceptual metaphors $A \Rightarrow B$ the a priori element is given as the inferential structure of the source domain 
A that is employed for the exploration of the target domain B. I do not contend, of course, that the approach based on conceptual metaphors and that on P/A-pairs are identical. This is certainly not the case. For instance, Lakoff and Núñez concentrate on the constitution of mathematical concepts, while Chang's P/A-pairs pairs have a broader scope. They contend to be relevant for all kinds of epistemological activities. This difference should not be regarded as a serious obstacle for the project of developing a unifying perspective that covers them both, or so I want to argue - with some help of Cassirer and Chang.

There is no reason to believe that conceptual metaphors are not restricted to the domain of mathematics. At least in the empirical sciences in which mathematics plays an indispensable role it is to be expected that conceptual metaphors play an analogous role in the constitution of empirical knowledge as they do in mathematial knowledge. But, as P/A-pairs remind us, devices like metaphors and principle-activity pairs can be found in every cognitive endeavor. This is not to deny that there are differences between them - probably the metaphorical constitution of empirical knowledge is more complex than that of purely mathematical knowledge. It may be that the indispensable role of experimental settings for empirical knowledge requires an adaption of the conceptual tools that describe the constitution of traditional mathematical knowledge. But there is no reason to expect that the constitutions in both realms were essentially different. Indeed, more than one hundred years ago Cassirer put forward the thesis that the constitutional methods in both realms are the same:

Only when we have understood that the same foundational syntheses on which logic and mathematics rest also govern the scientific construction of experiential knowledge, that only they enable us to speak of a strict, lawful ordering among appearances and therewith of their objective meaning: only then the true justification of the principles is attained. (Cassirer 1907, 44)

Or, to put it in the vernacular of this paper, a theory of the relative a priori of empirical knowledge should be cast in the theoretical framework of principle-activity pairs and conceptual metaphors.

6. Conceptual Metaphors and Category Theory. In order to elucidate further the structure of conceptual metaphors (and of principle-activity pairsP/A-pairs) in the rest of this section I'd like to show that the "metaphorical" constitution of mathematical concepts has striking 
affinities with the foundational account of category theory inaugurated in the 1940s by Saunders Mac Lane and Samuel Eilenberg (Mac Lane 1986, Awodey 2010). More precisely, conceptual metaphors have the same formal structure as functors in category theory. This is hardly a co-incidence (cf. Lakoff 1986), and leads to interesting ramifications for a comprehensive theory of the a priori, which can be pointed at here only in briefest outline.

According to Mac Lane, one of the great figures of $20^{\text {th }}$ century mathematics, the real nature of mathematical concepts does not reside in their set-theoretical formalization but in their relation to basic human activities. In terms of Lakoff and Núñez's approach based on the notion of conceptual metaphors this means that the important point for understanding mathematics is to make explicit the grounding conceptual metaphors of the various mathematical disciplines. In Mathematics - Form and Function (Mac Lane 1986) the author points out that mundane human activities such as collecting, computing, observing, measuring etc. give rise to the mathematical disciplines such as set theory, arithmetics, the theory of transformation groups, the theory of metric spaces, etc. (ibid. 35). His proposal to make explicit the natural sources of mathematical knowledge may be understood as the first step to conceive mathematical knowledge as part of an embedded human reason. The cognitive semantics of Lakoff and his collaborators makes an essential step beyond Mac Lane by offering us a detailed empirical theory, based on the findings of cognitive science and neuroscience, of how we succeeded to erect the aweful edifice of modern mathematics from the humble beginnings of the elementary activities of collecting, measuring, observing and so on.

Category theory enters the stage by offering a means for describing the structure of conceptual metaphors in detail. Recall that a conceptual metaphor $A \Rightarrow B$ is to use the inferential structure of the source domain A to reason about the target domain B. This idea of transfering (inferential) structures from one domain to another is captured by notion of a functor that may be considered as basic concept of category theory. For the sake of definiteness, let us succinctly recall the relevant definitions:

(6.1) Definition. A category A consists of the following data:

- Objects: A, B, C, ...

- Arrows: $f, g, h, \ldots$

- For each arrow $f$, there are given objects dom(f), $\operatorname{cod}(f)$ called the domain and the codomain of $f$. Then $f: A \rightarrow B$ indicates that $A$ is the domain and $B$ is the codomain of $f$. 
- Given arrows $f: A \rightarrow B$ and $g: B \rightarrow C$ there is an arrow $g \cdot f: A \rightarrow C$ called the composite of $f$ and $g$. For each object $A$ there is an arrow $1_{A}: A \rightarrow A$ called the identity arrow of $\mathrm{A}$.

These data are required to satisfy the following laws:

- Associativity: $(h \bullet g) \bullet f=h \bullet(g \bullet f)$ for all $f: A \rightarrow B$ g: $B \rightarrow C, h: C \rightarrow D$.

- Unit: $1_{A} \cdot f=f \cdot 1_{A}$ for all $f: A \rightarrow B$.

Intuitively, categories may be conceived as "universes of (mathematical) discourse" giving us a frame for talking about objects and their relations. Categories abound in mathematics and elsewhere. Ample lists of categories can be found in every textbook of this subject (cf. Awoday 2010, Mac Lane 1986). The real usefulness of the category-theoretical perspective shows up, if one has to deal with relations between various universes of discourse. A translation from one universe of discourse to another one is defined as a functor, i.e. a "homomorphism of categories":

(6.2) Definition. A functor F: $\mathbf{C} \Rightarrow \mathbf{D}$ between categories $\mathbf{C}$ and $\mathbf{D}$ is a mapping of objects to objects and arrows to arrows, in such a way that

- $F(f: A \rightarrow B)=F(f): F(A) \rightarrow F(B)$

- $F\left(1_{A}\right)=1_{F(A)}$

- $F(g \cdot f)=F(g) \cdot F(f)$

In a similar way as the arrows of a category functors F: $\mathbf{C} \Rightarrow \mathbf{D}$ and $\mathrm{G}: \mathbf{D} \Rightarrow \mathbf{E}$ may be concatenated to yield a functor $\mathrm{G} \cdot \mathrm{F}: \mathbf{C} \Rightarrow \mathbf{E}$. In this manner complex networks of categories related by various functors can be built up. As has been shown in the last forty years or so, this austere base suffices to reconstruct large parts of mathematics as a complex net of functors (cf. Adamek, Herrlich and Strecker 1990). Indeed, the functorial transfer of structures is a familiar procedure in the practice of contemporary mathematics. In particular, the study of functorial relations between geometrical and algebraic categories has led to tremendous progress in both areas.

In the last decades ample evidence has been gathered that the usefulness of categorytheoretical concepts is in no way restricted to the realm of mathematics. Rather, categorytheoretical methods spread into various other disciplines such as computer science, lingu- 
istics, cognitive science, philosophy and many other areas. This may be taken as a confirmation of Cassirer's sameness thesis according to which in both realms of scientific knowledge essentially the same constitutions are operative. Be this as it may, it should give at least some initial plausibility to the following proposal:

(6.3) Proposal. Conceptual metaphors $A \Rightarrow B$ can be considered as functors in the sense of category theory. The source domain $\mathbf{A}$ and the target domain $\mathbf{B}$ are to be conceived as categories and the transfer from the interferential structure of the former to the latter is conceived as a functor between them.

In other words, our excursion into the category-theoretical foundations of mathematics should not be considered as an idle detour into alien territory but as an attempt for tapping some new conceptual sources in order to accomplish our original task, the elucidation of the structure of the relative a priori in empirical sciences.

7. Concluding Remarks. Let us have a look back on the road that we have walked down in search for an adequate formulation of the a priori element in scientific knowledge. It started with Kant's synthetic a priori characterized as universal, constitutive, regulative and apodictic element of scientific knowledge. Due to the post-Kantian developments in the empirical sciences, logic and mathematics the Kantian proposal came under heavy attack from various quarters. In particular, the apodictic character of the Kantian a priori was considered as untenable by virtually all currents of post-Kantian philosophy of science. On the other hand, the other aspects of the Kantian a priori survived in some form or other well into the $20^{\text {th }}$ century and are living on up to this day. For instance, even philosophers who dismissed the rest of Kantian philosophy of science as obsolete subscribed to a constitutive a priori in some form or other. Perhaps the most prominent example group was Reichenbach, at least during a certain stage of his philosophical career. Other logical empiricists such as Schlick and Carnap had a less positive assessment of this remaining Kantian ingredient in modern philosophy of science. Nevertheless, as been pointed out by Friedman and others, even in Carnap's mature philosophy one finds a Kantian a priori in disguise in the notion of linguistic (or ontological) frameworks (cf. Friedman 2001). Indeed, as Coffa observed, the a priori element is a kind of protean entity that shows up in a variety of versions in virtually every current of $20^{\text {th }}$ century 
philosophy of science, although, of course, not necessarily under that name. A rather neglected version has been Lewis's pragmatic a priori (Lewis 1929). Both Carnap's and Lewis's accounts of the a priori are non-apodictic, relativized, and constitutive. An important difference, however, is that Carnap's a priori is cast into a strictly theoretical account of scientific knowledge. Carnap explicitly excluded pragmatic aspects of knowledge from the proper realm of science; and consequently they were not an issue for philosophy of science proper (cf. Carnap 1935). This attitude was in stark contrast with the pragmatist philosophy of science. Pragmatists like James, Dewey, or Lewis subscribed to a different conception of knowledge vigorously put forward by Lewis at the very beginning of An Analysis of Knowledge and Valuation (Lewis 1946):

Knowledge, action, and evaluation are essentially connected. The primary and pervasive significance of knowledge lies in its guidance of action; knowing is for the sake of doing. And action, obviously, is rooted in evaluation. For a being which did not assign comparative values, deliberate action would be pointless; and for one which did not know, it would be impossible. Conversely, only an active being could have knowledge, and only such a being could assign values to anything beyond his own feelings. (Lewis 1946, 5)

As Lewis's account evidences pragmatic aspects of scientific knowledge does not leave its a priori element untouched. Pragmatization renders untenable to conceive the a priori as a universal and eternal contribution provided by a general transcendental reason. Rather, the $a$ priori becomes a component of knowledge rooted in the contingent and local character of an "embedded reason" which conceives our rationality as the rationality of a finite species living in a contingent material world. This idea, which may be traced back to Lewis, is further elaborated by Chang in his paper Contingent Transcendental Arguments for Metaphysical Principles. There, Chang proposes to elaborate and systematize Lewis's pragmatic a priori through the concept of "principle-activity pairs" (P/A-pairs).

A major thesis brought forward in this paper contends that P/A-pairs are closely related to conceptual metaphors $B \Rightarrow C$ that play a central role in the cognitive semantics of Lakoff and Núñez. Their account seeks to explain the constitution of (mathematical) concepts in a naturalistic framework of an "embedded reason" that strongly depends on the biological and environmental contingencies of the species to which it belongs. As it turns out, the structure 
of conceptual metaphors $B \Rightarrow C$ can be further elucidated with the aid the concept of a functor F: $\mathbf{D} \Rightarrow \mathbf{E}$ borrowed from category theory.

In sum, then, today a rich arsenal of conceptual tools is available for explicating the function and structure of the a priori element in scientific knowledge. If this is true, the Kantian legacy of the a priori may be relevant even for $21^{\text {rst }}$ century philosophy of science.

\section{Bibliography}

Adamek, J., Herrlich, H., Strecker, G.E., 1990, Abstract and Concrete Categories, New York, Wiley.

Baldwin, T., 2007, "C.I. Lewis: Pragmatism and Analysis", in M. Beaney, The Analytic Turn. Analysis in Early Analytic Philosophy and Phenomenology (ed.), London, Routledge, 178 195.

Carnap, R., 1935, Philosophy and Logical Syntax, London, Kegan, Trench and Trubner.

Carnap, R., 1950, "Empiricism, Semantics, and Ontology", in Revue International de Philosophie 4, $20-40$.

Cassirer, E., 1907, "Kant und die moderne Mathematik", in Kant-Studien 12, 1 - 49.

Cassirer, E. 1910(1953), Substance and Function, New York, Dover.

Cassirer, E., 1921, Zur Einsteinschen Relativititätstheorie. Erkenntnistheoretische Betrachtungen, Berlin, Bruno Cassirer. Translated as Einstein's Theory of Relativity, Chicago and LaSalle, Open Court.

Chang, H., 2008, “Contingent Transcendental Arguments", in M. Massimi (ed.), Kant and Philosophy of Science Today, Royal Institute of Philosophy Supplement 63, $113-133$.

Friedman, M., 2001, Dynamics of Reason, Stanford/California, CSLI Publications.

Ihmig, K.-N., 1997, Cassirers Invariantentheorie der Erfahrung und seine Rezeption des "Erlanger Programms", Hamburg, Meiner.

Kuhn, T., 1962, The Structure of Scientific Revolutions, Chicago, University of Chicago Press. Second edition, 1970.

Lakoff, G., 1987, Women, Fire, and Dangerous Things. What Categories Reveal about the Mind, Chicago, The University of Chicago Press.

Lakoff, G., Núñez, R.E., 2000, Where Mathematics Comes From. How the Embodied Mind Brings Mathematics Into Being, New York, Basic Books. 
Lewis, C.I., 1922, “A Pragmatic Conception of the A priori”, in Journal of Philosophy 20, 169 177. Reprinted in Lewis 1970, 231 - 239.

Lewis, C.I., 1926, "The Pragmatic Element in Knowledge", in University of California Publications in Philosophy 6, 205 - 227. Reprinted in Lewis 1970, 240 - 257.

Lewis, C.I., 1929 (1956), Mind and the World Order. Outline of a Theory of Knowledge, New York, Dover.

Lewis, C.I., 1941, “Logical Positivism and Pragmatism”, Reprinted in Lewis 1970, 92 - 112.

Lewis, C.I., 1970, Collected Papers of Clarence Irving Lewis, Edited by John D. Goheen and John L. Motherhead, Jr., Stanford, Stanford University Press.

Mac Lane, S., 1986, Mathematics. Form and Function, Berlin and New York, Springer.

Mormann, T., 1997, “Der begriffliche Aufbau der wissenschaftlichen Wirklichkeit bei Cassirer", in Logos. Zeitschrift für systematische Philosophie 5, 268 - 293.

Mormann, T., 2007, "Carnap's logical empiricism, values, and American pragmatism", in Journal of General Philosophy of Science 38, 127 - 146.

Mormann, T., 2008, “Idealization in Cassirer's Philosophy of Mathematics", in Philosophia Mathematica (III) 16, 151 - 181.

Murphey, G.M., 2005, C.I. Lewis. The Last Great Pragmatist, State University Press of New York, New York.

Reichenbach, H., 1921, The Theory of Relativity and A Priori Knowledge. English Translation by M. Reichenbach, 1965, Berkeley, University of California Press.

Rosenthal, S.B., 2007, C.I. Lewis in Focus. The Pulse of Pragmatism, Bloomington/Indiana, Indiana University Press.

Schlick, M., 1921, "Kritizistische oder empiristische Deutung der neuen Physik? Bemerkungen zu Ernst Cassirers Buch "Zur Einsteinschen Relativititätstheorie"”, in Kant-Studien 26, 96 111.

Stump, D.J., 2003, "Defending Conventions as Functionally A priori Knowledge”, in Philosophy of Science 70 (5), $1149-1160$. 